\title{
Comparative Study of Histopathological Patterns and Mast Cells in Cutaneous Lichen Planus and Lichenoid Lesions
}

\author{
Balasubrahmaniyam Priya ${ }^{1}$, T.B. Uma Devi ${ }^{1}$, Karthikeyan $\mathrm{K}^{2}$ and Mourouguessine Vimal ${ }^{1 \text { * }}$ \\ ${ }^{1}$ Department of Pathology, Sri Manakula Vinayagar Medical College and Hospital, Puducherry, India. \\ ${ }^{2}$ Department of Dermatology, Sri Manakula Vinayagar Medical College and Hospital, Puducherry, India.
}

\begin{abstract}
Background: Besides lichen planus various other skin lesions like erythema multiforme, pityriasis lichenoides, etc., show lichenoid reaction pattern. This study was aimed to compare the histological features and number of mast cells in cutaneous lichen planus and lichenoid lesions. Studies have shown increase in mast cell numbers in mucosal lichen planus and lichenoid lesions.

Methods: Tissue sections of lichen planus and lichenoid lesions, (forty samples for each group) were studied. All the epidermal, dermal changes and mast cell numbers were noted.

Results: Epidermal and dermal changes like acanthosis, hypergranulosis, hyperkeratosis, location of inflammatory cells, severity of inflammation and basement membrane thickness were statistically significant between the two groups. Cases with severe inflammation showed thin and disrupted basement membrane, severe capillary proliferation and severe basal cell vacuolation. The number of mast cells was not significant on comparison between the two groups.

Conclusion: The epidermal and dermal changes were consistent with usual histopathological findings in these lesions. The mast cell number was not significant on comparison, which may be due to the common and overlapping mechanisms in the pathogenesis of inflammation in both the groups.
\end{abstract}

Keywords: Lichenoid Reaction, Lichen Planus, Interface Dermatitis, Mast Cells.

\section{Introduction}

The lichenoid lesions show the characteristic basal cell vacuolar degeneration and a band of interface inflammation. Lichen planus forms the biggest group in this category. It is a chronic dermatosis with a female preponderance. Lichenoid dermatosis includes a variety of lesions like lichenoid drug eruption, pityriasis lichenoides, lichenoid keratosis, etc.

The mast cells play multiple immunological roles in various anatomical sites. Studies showed significantly increased mast cell number in oral lichen planus lesions compared to the normal mucosa. Attempts were also made to study the number of mast cells for the comparison of oral lichen planus and lichenoid lesion. ${ }^{[1-4]}$ Mast cells secrete various cytokines, chemokines and enzymes that may cause progression of inflammation in these cases. ${ }^{[5-7]}$

\section{Aims and Objectives}

1) To compare and correlate the histopathological parameters in the tissue sections of lichen planus and lichenoid lesions.; 2) To compare the basement membrane thickness and subepithelial vascularity in the two groups.; 3) To compare the total number and number of degranulated mast cells in both the groups.

\section{Materials and methods}

Histopathologically diagnosed cases of lichen planus and lichenoid lesions from the Pathology Department of a tertiary care hospital for a period of five years (2012-2016) were included in this study.

For each of the two groups- lichen planus and lichenoid lesions, 40 samples were taken and stained with Haematoxylin and Eosin $(\mathrm{H} / \mathrm{E})$ stain, Toluidine blue and Periodic Acid Schiff (PAS) stain. H/E stained slides were used to identify the histopathological parameters and their severity. PAS was used to stain the basement membrane and Toluidine blue, to stain the mast cells. The mast cells were grouped according to the intensity of metachromasia, as intact mast cells and degranulated mast cells. ${ }^{[3]}$

\section{Results}

Present study showed a female preponderance with $62.5 \%$ of females and $37.5 \%$ of males, out of the total 80 patients, $75 \%$ of subjects in lichen planus group and $55 \%$ in lichenoid group were middle aged $(20-50$ years $)$. Tables 1 to 3 show the histopathological parameters compared between the two groups.

The mean value of the mast cells (Figure-1) in both the groups was nearly equal (49 in lichen planus and 48 in 
lichenoid lesion group) with a standard deviation of 19 in lichen planus group and 14 in lichenoid group. The mean number of degranulated mast cells in lichen planus group was 26 and that of lichenoid group was 24 .

About $62 \%$ of cases with severe inflammation showed moderate acanthosis and $44.8 \%$ of cases with moderate inflammation showed mild acanthosis. The significant $\mathrm{p}$ value for this association was less than 0.001 . Around $55.2 \%$ of cases with severe inflammation showed moderate hypergranulosis and $68.2 \%$ of cases with mild inflammation did not show hypergranulosis. p value was $<0.001$.

Majority of cases with mild inflammation showed normal $(50 \%)$ and focal disruption of basement membrane (45.5\%). 58.6\% of cases with severe inflammation showed thinned and disrupted basement membrane (Figure-2). p value was $<0.01$.

Approximately $66 \%$ cases with severe inflammation showed severe basal cell degeneration. $62 \%$ of cases with moderate inflammation showed moderate basal cell degeneration and $54.5 \%$ of cases with mild inflammation showed mild basal cell degeneration, $\mathrm{p}$ value being $<0.01$.
In cases of severe inflammation, $34.5 \%$ showed loss of rete followed by $31 \%$ showing thin and serrated rete. $41 \%$ of cases with moderate inflammation showed focal loss of rete. $40 \%$ of cases with mild inflammation showed fused and blunt rete, ( $\mathrm{p}$ value $<0.01$ ).

Around $75.9 \%$ of cases with severe inflammation show severe capillary proliferation and $62 \%$ of cases with moderate severity show moderate capillary proliferation. The significant $\mathrm{p}$ value was $<0.01$.

About $58.8 \%$ of cases with severe capillary proliferation showed severe basal cell degeneration and $50 \%$ of cases with moderate capillary proliferation showed moderate basal cell degeneration. Significant association was seen with a $\mathrm{p}$ value of 0.001 .

On comparing the relation of location of inflammatory cells and basement membrane thickness, $68.4 \%$ of cases with normal basement membrane thickness showed perivascular inflammation. $50 \%$ of cases with thin and disrupted basement membrane showed interface inflammatory infiltrates ( $p$ value $<0.001$ ).

Table 1: Comparison of epidermal changes among the study participants $(\mathrm{N}=80)$. $\mathrm{N}$ (Number), \% (Percentage).

\begin{tabular}{|c|c|c|c|}
\hline Epidermal changes & Lichen planus $\mathbf{N}(\%)$ & Lichenoid lesion N (\%) & p Value \\
\hline \multicolumn{4}{|c|}{ Acanthosis } \\
\hline Nil and mild & $10(25)$ & $26(65)$ & 0.003 \\
\hline Moderate and severe & $30(75)$ & $14(35)$ & \\
\hline \multicolumn{4}{|l|}{ Hypergranulosis } \\
\hline Nil and mild & $18(45)$ & $30(75)$ & 0.005 \\
\hline Moderate and severe & $22(55)$ & $10(25)$ & \\
\hline \multicolumn{4}{|c|}{ Hyperkeratosis } \\
\hline Nil and mild & $13(32.5)$ & $27(67.5)$ & 0.019 \\
\hline Moderate and severe & $27(67.5)$ & $13(32.5)$ & \\
\hline \multicolumn{4}{|c|}{ Basal cell degeneration } \\
\hline Nil and mild & $8(20)$ & $11(27.5)$ & 0.575 \\
\hline Moderate and severe & $32(80)$ & $29(72.5)$ & \\
\hline
\end{tabular}

Table 2: Comparison of dermal changes among the study participants $(\mathrm{N}=80)$. $\mathrm{N}$ (Number), \% (Percentage).

\begin{tabular}{|c|c|c|c|}
\hline Dermal changes & Lichen planus $\mathbf{N}(\%)$ & Lichenoid lesion $\mathbf{N}(\%)$ & p Value \\
\hline \multicolumn{4}{|c|}{ Severity of inflammation } \\
\hline Mild and moderate & $17(42.5)$ & $34(85)$ & \multirow[t]{2}{*}{$<0.001$} \\
\hline Severe & $23(57.5)$ & $6(15)$ & \\
\hline \multicolumn{4}{|c|}{ Location of inflammatory cells } \\
\hline Interface & $13(32.5)$ & $11(27.5)$ & \multirow[t]{3}{*}{$<0.001$} \\
\hline Perivascular & $3(7.5)$ & $19(47.5)$ & \\
\hline Interface and perivascular & $24(60)$ & $10(25)$ & \\
\hline \multicolumn{4}{|c|}{ Dermal edema } \\
\hline Nil and mild & $32(80)$ & $29(72.5)$ & \multirow[t]{2}{*}{$=0.73$} \\
\hline Moderate & $8(20)$ & $11(27.5)$ & \\
\hline
\end{tabular}


Table 3: Comparison of distribution of basement membrane thickness and subepithelial vascularity among the study participants $(\mathrm{N}=80)$. $\mathrm{N}$ (Number), \% (Percentage).

\begin{tabular}{|c|c|c|c|}
\hline & Lichen Planus N (\%) & Lichenoid lesions N (\%) & p Value \\
\hline \multicolumn{4}{|c|}{ Basement membrane thickness } \\
\hline Normal & $4(10.0)$ & $15(37.5)$ & \multirow{3}{*}{0.0002} \\
\hline Thinned and disrupted & $21(52.5)$ & $5(12.5)$ & \\
\hline Focal disruption & $15(37.5)$ & $20(50.0)$ & \\
\hline \multicolumn{4}{|c|}{ Capillary proliferation } \\
\hline Mild and moderate & $18(45)$ & $28(70)$ & \multirow{2}{*}{0.03} \\
\hline Severe & $22(55)$ & $12(30)$ & \\
\hline
\end{tabular}

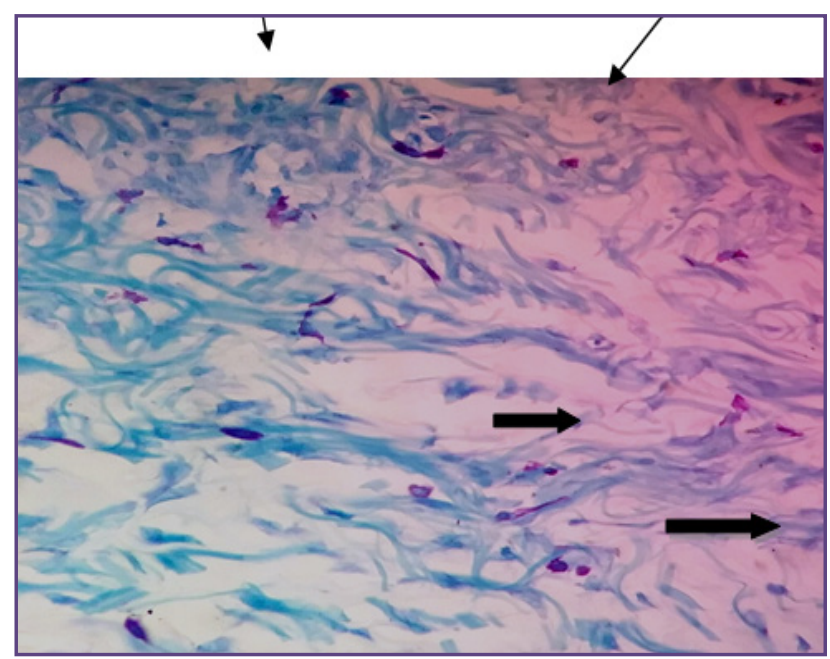

Fig. 1: Lichen planus- degranulated (thin arrow) and intact (block arrow) mast cells (Toluidine blue, high power).

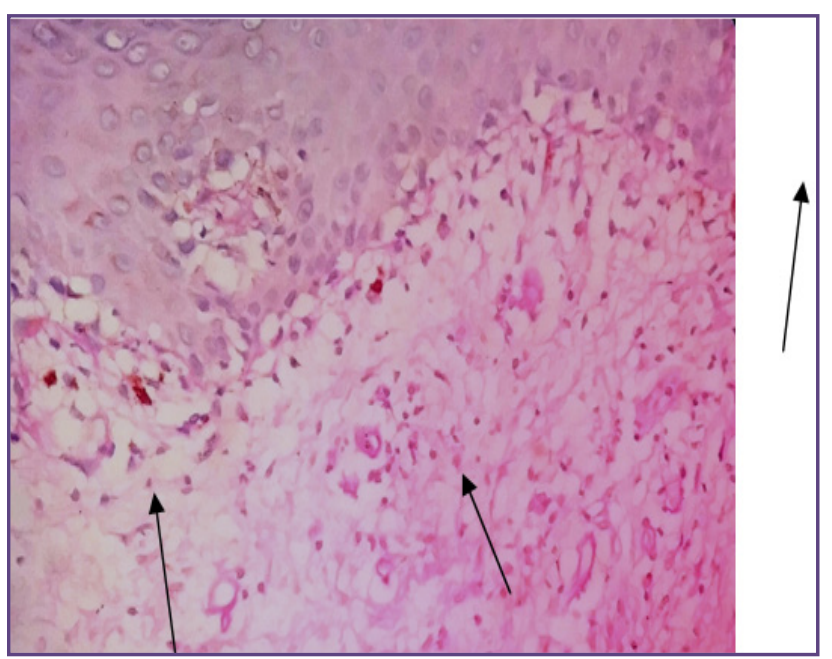

Fig. 2: Lichen planus- Basement membrane disruption (arrows) (PAS, high power)

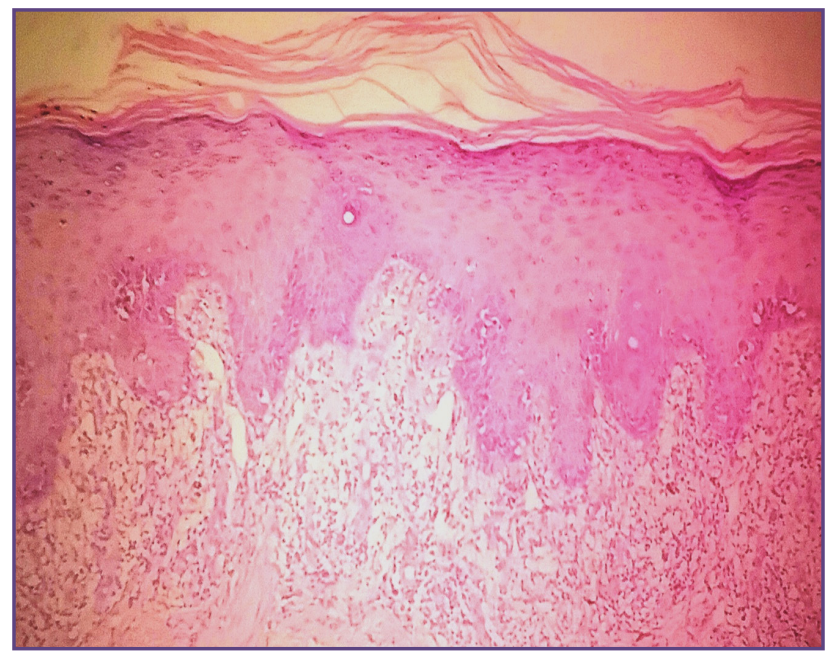

Fig. 3: Lichen planus - Mild Hyperkeratosis, moderate acanthosis, moderate hypergranulosis, moderate basal cell vacuolation and severe interface inflammation $(\mathrm{H} / \mathrm{E}$, high power). 


\section{Discussion}

Consistent with other observations in literature, our study showed a female preponderance $(62.5 \%)$. In a study of lichenoid tissue reaction by Kumar et a ${ }^{[8]}, 38$ were males, 52 were females. Similarly Parihar et $\mathrm{al}^{[9]}$ showed male to female ratio of $0.8: 1$. This can be associated with the autoimmune hypothesis in the evolution of these lesions. ${ }^{[10]}$

Boyd et $\mathrm{al}^{[11]}$ observed that lichen planus most commonly affects middle-aged subjects with children consisting of only $2 \%-3 \%$ of the patients. In a study by Sehgal et al ${ }^{[12]}$ , $46 \%$ of patients with lichenoid tissue reaction were in the age group $21-40$ years, which included both lichen planus and lichenoid lesions. Kacchawa et al ${ }^{[13]}$ in a study noted $47 \%$ of subjects in the range of $20-39$ years. These findings are similar to the present study.

Epidermal changes: On comparison of the epidermal changes between the two groups, hyperkeratosis, hypergranulosis and acanthosis are seen to a moderate or severe degree in lichen planus and absent or mild in lichenoid lesions. All the cases included in the study showed basal cell vacuolation except two cases in the lichenoid group.

Wedge shaped hypergranulosis (Figure-3) is a constant finding in lichen planus. Present study showed $77.5 \%$ of cases of lichen planus showing hypergranulosis. Gupta et $\mathrm{al}^{[14]}$, Parihar et al ${ }^{[9]}$, Gurusamy et $\mathrm{al}^{[15]}$ and Karumbaiah et $\mathrm{al}^{[16]}$ showed hypergranulosis of $86 \%, 96.5 \%, 80 \%$ and $76.47 \%$ respectively in their study of lichen planus. Prominent granular layer is considered to be the cause of Wickham's striae seen in clinical lesions. ${ }^{[17]}$

However in case of lichenoid lesions like lichenoid drug eruption, lichenoid keratosis, lichen sclerosus et atrophicus granular layer is minimal to absent. ${ }^{[17]}$ Accordingly, present study showed hypergranulosis in $40 \%$ of cases with lichenoid lesions. In studies of lichenoid tissue reaction or interface dermatitis by other authors, like Chauhan et al ${ }^{[18]}$, $65.15 \%$ of hypergranulosis was noted. Higher number of cases showing hypergranulosis in Chauhan's study may be due to the major fraction of lichen planus cases included, compared to other lichenoid lesions. Studies on lichenoid lesions excluding lichen planus is sparse.

Acanthosis (Figure-3) was found in $97.5 \%$ and $85 \%$ of cases of lichen planus and lichenoid lesions respectively in the present study. Similarly Parihar et al ${ }^{[9]}$ noted $94 \%$ of lichen planus lesions showing acanthosis. Gupta et $\mathrm{al}^{[14]}$ and Gurusamy et $\mathrm{al}{ }^{[15]}$ recorded $88 \%$ and $78 \%$ of acanthosis in lichen planus cases respectively.

Notable acanthosis is not seen in lichenoid lesions, while few of them like lichen sclerosus et atrophicus and Kyrle's disease show thinning of the epidermis. ${ }^{[17]}$ Kumar et al ${ }^{[8]}$ noted $83 \%$ of acanthosis in their study of lichenoid lesions and $68 \%$ were reported by Hegde et $\mathrm{al}^{[19]}$ in lesions of interface dermatitis. The present study showed $85 \%$ of lichenoid lesions with acanthosis.

Basal cell degeneration (Figure-3) is the classical feature of lichenoid tissue reaction. It was noted in all (100\%) the lichen planus lesions studied. In lichenoid lesions, $97.5 \%$ of cases show basal cell vacuolar degeneration. Keratinocytes are the principal targets of the immune activation triggered by a variety of antigenic stimuli in the spectrum of lichenoid tissue reaction. The mechanism of basal cell damage as caused by necrosis or apoptosis is still debated. Studies have shown increased CD4/CD8 $\mathrm{T}$ lymphocytes in these lesions in variable proportions in each condition. Also antigen presenting langerhans cells are found increased just prior to the inflammatory cell accumulation. ${ }^{[17,20]}$

In study of lichenoid lesions, Chauhan et al ${ }^{[18]}$, Kumar et $\mathrm{al}^{[8]}$ and Hegde et $\mathrm{a}^{[19]}$ reported $74.24 \%, 96.6 \%$ and $100 \%$ of cases showing basal cell liquefactive degeneration respectively. Similarly in studies of lichen planus lesions also, Gurusamy et al ${ }^{[15]}$, Karumbaiah et $\mathrm{al}^{[16]}$ and Parihar et $\mathrm{al}^{[9]}$ showed $100 \%$ association with vacuolar degeneration of the basal layer.

Dermal Changes: Significant parameters on comparison were severity of inflammation and the location of inflammatory cells. Lichen planus shows band of severe interface inflammation. In lichenoid lesions like erythema multiforme, lichen sclerosus et atrophicus and pityriasis lichenoides chronica et varioliformis acuta (PLEVA) initial leions show heavy interface inflammation. On progression of the lesion, inflammation reduces with predominant perivascular infiltrates.

Presence of band like inflammatory infiltrates (Figure-3) in the interface was reported in $92 \%, 94 \%, 82.36 \%$ of lichen planus lesions by Gupta et $\mathrm{al}^{[14]}$, Parihar et $\mathrm{a}^{[9]}$ and Karumbaiah et al ${ }^{[16]}$ respectively. Our study showed $92.5 \%$ of cases with interface inflammation, with a high fraction of them $(60 \%)$ showing inflammation both in interface and perivascular foci rather than strict interface inflammation $(30 \%)$.

Significant Associations found in the study: There were significant associations between the severity of inflammation and histological parameters like acanthosis, hypergranulosis, basement membrane thickness, capillary proliferation, basal cell degeneration and morphology of rete. Also, there was an association between basement membrane thickness and the location of inflammatory 
cells. These findings reiterate the basic pathogenesis wherein the cytotoxic $\mathrm{T}$ cells cause damage to the basal keratinocytes. ${ }^{[20]}$ Hence the histopathological changes were strongly associated with the severity of inflammation and location of inflammatory cells.

Basement Membrane Thickness and Subepithelial vascularity: As shown in this study the severity of inflammation correlates with the basement membrane thickness, which can be highlighted here to understand that, lichen planus lesions, majority of which showed severe or moderate inflammation had disrupted basement membrane. However it is known that lichenoid lesions like lichen sclerosus et atrophicus or discoid lupus erythematosus show a thickened basement membrane and also majority of lichenoid lesions show perivascular infiltrates. ${ }^{[17]}$ Hence, the lichenoid lesions show either normal or focally disrupted basement membrane as shown (Table -3).

This study shows that lichenoid lesions have predominantly mild to moderate capillary proliferation (Table -3). Arguably lichen planus lesions with severe inflammation in many cases showed severe capillary proliferation correspondingly.

Mast Cells: Mast cells release TNF- $\alpha$, that can induce endothelial leukocyte adhesion molecule (ELAM) and vascular cell adhesion molecule (VCAM), for the binding of leukocytes and contributing to the progression of inflammation. Mast cell protease, tryptase has an angiogenic property, whereas chymase may lead to epithelial basement membrane damage. Mast cell mediators like histamine, heparin and TNF $\alpha$ are also mitogenic for endothelial cells and fibroblasts. ${ }^{[4-7]}$

Hence mast cells can logically explain the histopathological changes like basement membrane damage or increased vascularity observed here, however mast cell numbers were not significant on comparison between the two groups which may be due to similar pathogenesis with interplay of several effector cells, including mast cells in the causation of inflammation in both groups. More so, mast cells could also be innocent by standers in this cascade of inflammatory damage. Also mast cells are commonly seen in the early stages of several inflammatory reactions and hence, the timing of biopsy, which is mostly a few weeks after the lesions develop clinically, can also add to the reason.

\section{Conclusion}

Our observations showed a significant difference in histological features like hypergranulosis, acanthosis, severity of inflammation and location of inflammatory cells on comparison between the cutaneous lichen planus and lichenoid group. Significant associations between the severity of inflammation and histopathological parameters like basal cell damage and basement membrane thickness was found which is consistent with the inflammation driven damage to the basal keratinocytes. However the mast cell numbers did not showed a significant difference between the two groups.

\section{Conflict of interest}

The authors declare that there is no conflict of interest.

\section{References}

1. Zhao ZZ, Savage NW, Sugerman PB, Walsh LJ. Mast cell/T cell interactions in oral lichen planus. J Oral Pathol Med 2002;31:189-95

2. Sharma R, Sircar K, Singh S, Rastogi V. Role of mast cells in pathogenesis of oral lichen planus. J Oral Maxillofac Pathol 2011;15(3):267-71.

3. Jahanshahi G, Ghalayani P, Maleki L. Mast cells distribution and variations in epithelium thickness and basement membrane in oral lichen planus lesion and oral lichenoid reaction. Dent Res J 2012;9(2):180-4.

4. Juneja M, Mahajan S, Rao NN, George T, Boaz K. Histochemical analysis of pathological alterations in oral lichen planus and oral lichenoid lesions. J Oral Sci 2006;48(4):185-93.

5. Skokos D, Le Panse S, Villa I, Rousselle JC, Peronet R, David B, Namane A, Mécheri S. Mast cell-dependent B and $\mathrm{T}$ lymphocyte activation is mediated by the secretion of immunologically active exosomes. The Journal of Immunology. 2001 Jan 15;166(2):868-76.

6. Caughey GH. Mast cell tryptases and chymases in inflammation and host defense. Immunological reviews. 2007 Jun 1;217(1):141-54

7. Iddamalgoda A, Le QT, Ito K, Tanaka K, Kojima H, Kido $\mathrm{H}$. Mast cell tryptase and photoaging: possible involvement in the degradation of extra cellular matrix and basement membrane proteins. Archives of dermatological research. 2008 Apr 1;300(1):69-76.

8. Kumar M, Yelikar BR, Inamadar AC, Umesh S, Singhal A, Kushtagi AV. A clinico-pathological study of lichenoid tissue reactions-A tertiary care experience. Journal of clinical and diagnostic research: JCDR. 2013 Feb;7(2):312.

9. Parihar A, Sharma S, Bhattacharya SN, Singh UR. A clinicopathological study of cutaneous lichen planus. Journal of Dermatology \& Dermatologic Surgery. 2015 Jan 31;19(1):21-6.

10. Shiohara T, Mizukawa Y. The immunological basis of lichenoid tissue reaction. Autoimmunity reviews. 2005 Apr 30;4(4):236-41.

11. Boyd AS, Neldner KH. Lichen planus. Journal of the American Academy of Dermatology. 1991 Oct 1;25(4):593619.

12. Sehgal VN, Srivastava G, Sharma S, Sehgal S, Verma P. Lichenoid tissue reaction/interface dermatitis: Recognition, 
classification, etiology, and clinicopathological overtones. Indian Journal of Dermatology, Venereology, and Leprology. 2011 Jul 1;77(4):418.

13. Kachhawa D, Kachhawa V, Kalla G, Gupta L. A clinicoaetiological profile of 375 cases of lichen planus. Indian Journal of Dermatology, Venereology, and Leprology. 1995 Sep 1;61(5):276.

14. Gupta S, Talanikar HV, Ghadgepatil S. An epidemio-clinical and histo-pathological study of lichen planus. Journal of Evolution of Medical and Dental Sciences. 2016 Nov 7;5(89):6645-51.

15. Gurusamy L, Selvaraj U. Clinicopathological Study of Lichen Planus in a Tertiary Care Center.Ravikant Chauhan SM, Ali NM, Bhat RM, Sukumar D. Clinicopathological study of lichenoid reactions: a retrospective analysis. J Evol Med Dental Sci. 2015;4:5551-62.
16. Karumbaiah KP, Anjum A, Mallikarjun M. A Clinicopathologic Study of Lichen Planus. Scholars Journal of Applied Medical Sciences. 2017 Mar;5(3F):1122-1126.

17. Weedon D. Weedon's skin pathology. 3rd ed. China: Churchill Livingstone Elsevier; 2010. p. 36-9.

18. Ravikant Chauhan SM, Ali NM, Bhat RM, Sukumar D. Clinicopathological study of lichenoid reactions: a retrospective analysis. $\mathrm{J}$ Evol Med Dental Sci. 2015;4:5551-62.

19. Hegde VK, Khadilkar UN. A clinicopathological study of interface dermatitis. Indian Journal of Pathology and Microbiology. 2014 Jul 1;57(3):386.

20. Sontheimer RD. Lichenoid tissue reaction/interface dermatitis: clinical and histological perspectives. Journal of Investigative Dermatology. 2009 May 31;129(5):1088-99.

*Corresponding author:

Dr. Mourouguessine Vimal, No.21, Narmatha street, Vasanthnagar, Muthialpet, Puducherry-605003, India

Phone: +91 9994083575

Email:drvimalm@gmail.com

Financial or other Competing Interests: None. 